\title{
The changing face of a rare disease: lymphangioleiomyomatosis
}

\author{
Sergio Harari ${ }^{1,3}$, Olga Torre ${ }^{1,3}$, Roberto Cassandro ${ }^{1}$ and Joel Moss ${ }^{2}$ \\ Number 3 in the series "Rare pulmonary diseases and orphan drugs" \\ Edited by S. Harari and M. Humbert
}

\author{
Affiliations: \\ ${ }^{1}$ Unità Operativa di Pneumologia e Terapia Semi-Intensiva Respiratoria, Servizio di Fisiopatologia Respiratoria \\ ed Emodinamica Polmonare, Ospedale San Giuseppe, MultiMedica IRCCS, Milan, Italy. \\ ${ }^{2}$ Cardiovascular and Pulmonary Branch, National Heart, Lung, and Blood Institute, National Institutes of \\ Health, Bethesda, MA, USA. \\ ${ }^{3}$ Both authors contributed equally.

\section{Correspondence:} \\ Sergio Harari, Unità Operativa di Pneumologia e Terapia Semi-Intensiva Respiratoria, Ospedale San Giuseppe \\ - MultiMedica, Via San Vittore 12, 20123 Milan, Italy. \\ E-mail: shararidilpolmone.it
}

ABSTRACT Lymphangioleiomyomatosis is a rare disease characterised by cystic destruction of the lung, lymphatic abnormalities and abdominal tumours. It affects almost exclusively females and can occur sporadically or in patients with tuberous sclerosis complex.

In the past decade remarkable progress has been made in understanding of the pathogenesis of this disease leading to a new therapeutic approach. This review summarises recent advances regarding pathogenic mechanisms and clinical manifestations, and highlights the current and the most promising future therapeutic strategies.

@ERSpublications

Recent advances in pathogenesis, clinical manifestations and therapeutic strategies of lymphangioleiomyomatosis http://ow.ly/Rbmlh

Previous articles in this series: No. 1: Collard HR, Bradford WZ, Cottin V, et al. A new era in idiopathic pulmonary fibrosis: considerations for future clinical trials. Eur Respir J 2015; 46: 243-249. No. 2: Ryerson CJ, Cottin V, Brown KK, et al. Acute exacerbation of idiopathic pulmonary fibrosis: shifting the paradigm. Eur Respir J 2015; 46: 512-520.

Received: March 132015 | Accepted after revision: July 112015 | First published online: Sept 242015

Conflict of interest: None declared.

Copyright @ERS 2015 


\section{Introduction}

Lymphangioleiomyomatosis (LAM) is a multisystem disease affecting almost exclusively women, it is characterised by proliferation of abnormal smooth muscle-like cells (LAM cells), leading to the formation of lung cysts, fluid-filled cystic structures in the axial lymphatics (i.e. lymphangioleiomyomas) and angiomyolipomas, which are benign tumours usually found in the kidneys [1,2]. It can be sporadic or occur in women with tuberous sclerosis complex (TSC), an autosomal dominant syndrome characterised by cerebral calcifications, seizures, mental retardation and hamartomatous lesions in various organs $[3,4]$. Sporadic LAM is uncommon in men [5-7]; however, cystic change suggestive of LAM has been recognised in $13 \%$ and $38 \%$ of men with TSC in two different retrospective studies, although LAM seems to be milder in men compared with women with TSC $[8,9]$. LAM was reported to affect about a third of women with TSC $[10,11]$, but recent findings in a large cohort of patients suggest that the prevalence of cystic changes consistent with LAM on computed tomography (CT) scans is higher and increase with age (up to $80 \%$ of subjects aged $>40$ years) [12]. TSC occurs in one in 5800 births, and sporadic LAM has a prevalence estimated to be between 3 and 7.8 per million women $[13,14]$. Despite the rarity of the disease, in the past decade, remarkable advances have been made regarding clinical presentation, pathogenetic mechanisms and therapeutic possibilities, mostly thanks to data collected worldwide by LAM associations, national registries and referral centres. In 2010, guidelines for the diagnosis, assessment and treatment of LAM were published by the European Respiratory Society (ERS) LAM Task Force. These guidelines defined diagnostic criteria and highlighted management approaches including follow-up and available treatment and its complications [15].

\section{LAM cells and pathogenesis of the disease}

LAM results from the proliferation of LAM cells, which include myofibroblast-like, spindle-shaped cells and epithelioid-like cells that express smooth muscle-specific proteins [16, 17]. The epithelioid cells also express oestrogen and progesterone receptors [17-19]. Glycoprotein gp100, a marker of melanoma cells and immature melanocytes, is found in LAM cells, and reacts with monoclonal HMB-45 [20, 21]. The spindle-shaped cells also express proliferating cell nuclear antigen, a marker of DNA synthesis and cell proliferation [20]. More recently, CD44v6, a glycoprotein that binds hyaluronic acid and is associated with metastatic cancers, has also been found on the LAM cell surface [22]. Osteopontin, a regulator of CD44 splicing, is elevated in serum, and matrix metalloproteinases (MMPs) are found in the LAM lung nodule and may be responsible for lung destruction [22, 23]. CD44v6 could be involved in pathogenesis of LAM by enabling LAM cells to adhere to the extracellular matrix, thereby facilitating their metastasis.

Indeed, several findings indicate that LAM cells can metastasise. Identical TSC2 mutations were found in lung lesions and angiomyolipomas from the same patient with sporadic LAM, and recurrent LAM cells of recipient origin were detected after lung transplantation in the donor lung [24-26]. LAM cells have been found in the blood, urine and chylous fluids of some LAM patients, demonstrating that LAM cells can leave primary lesions and disseminate through the lymphatics or blood vessels [27].

Understanding the genetic basis of LAM has been pivotal to progress in pathogenesis and potential therapeutic approaches. In the early 2000s, it was confirmed that LAM is characterised by mutations in the tuberous sclerosis genes TSC1 and, much more frequently, TSC2 causing the loss of function of either TSC1 or TSC2 gene products, which are known as hamartin and tuberin, respectively [28-31]. Tuberin is involved in the cell cycle and in cell growth and proliferation; hamartin is thought to have a role in the reorganisation of the actin cytoskeleton by inducing an increase in Rho-GTP levels and by binding activated ezrin/radixin/moesin proteins [2]. In vivo, hamartin and tuberin are part of a heterotrimer acting upstream of the intracellular serine/threonine kinase mammalian/mechanistic target of rapamycin (mTOR), whose major function is regulation of cell growth and proliferation mediated by growth factors, energy and stress signals. There are two complexes involving mTOR: mTORC1, which includes raptor (regulatory-associated protein of mTOR) and is sensitive to the mTOR inhibitor rapamycin; and mTORC2, which contains rictor (rapamycin-insensitive companion of mTOR) and is relatively insensitive to rapamycin [32, 33]. The hamartin-tuberin complex negatively regulates mTORC1 by stimulating GTP hydrolysis by the protein Rheb (Ras homolog enriched in brain) [34-36]. Inhibition of the hamartin-tuberin complex by growth factors through the mitogen-activated protein kinase (MAPK) and insulin-signalling pathways causes accumulation of active Rheb-GTP, which stimulates mTORC1 [35-38]. mTORC1 phosphorylates ribosomal S6 kinase and eukaryotic initiation factor 4E-binding protein, leading to enhanced translation [39]. The MAPK signalling pathway can activate mTORC1 without involving the hamartin-tuberin complex via RSK-catalysed phosphorylation of raptor, a component of the mTORC1 complex [40]. The insulin-signalling pathway can also activate mTORC1 directly by Akt-catalysed phosphorylation of PRAS40, an inhibitor of mTORC1, thereby relieving the inhibition. mTORC1 is a key inhibitor of autophagy via ULK1, and autophagy levels are low in TSC-deficient LAM cells [41-43]. 
Although most biochemical and signalling effects in cells lacking TSC1 or TSC2 products are thought to occur through activation of mTORC1, in the past few years mTORC1-independent mechanisms have been defined. Non-canonical, still less well-known functions of the hamartin-tuberin complex and Rheb include regulation of the cytoskeleton and RhoA via hamartin or TORC2, regulation of the primary cilium, and regulation of cellular differentiation and proliferation via B-Raf and Notch [44-50]. The hamartin-tuberin complex positively regulates mTORC2, which may have a role in actin dynamics, through activation of protein kinase $\mathrm{C} \alpha$ and Rac and Rho GTPases [51].

A Rheb-independent function of the hamartin-tuberin complex may be regulation of MMPs. MMPs are overexpressed in cells lacking TSC1/TSC2, and this overproduction is not affected by either Rheb knockdown or rapamycin [52]. MMPs have been implicated in the pathogenesis of LAM; they are present in LAM lesions, and are elevated in the blood and urine of patients with LAM $[23,53]$.

Recently, adipocyte phospholipase A2 (AdPLA2), a rate-limiting enzyme in the production of prostaglandins, has been shown to be upregulated in LAM lung nodules. This overexpression is TSC2 dependent and rapamycin insensitive in cell culture models [54]. This finding suggests that production of prostaglandins modulated by AdPLA2 may play a role in promoting tumorigenesis and disease progression in TSC and LAM.

Oestrogens are involved in the pathogenesis of LAM by interactions with signalling events in LAM cells. A role of oestrogens in LAM is suggested by its female predominance, its frequent occurrence during childbearing age, reported worsening of lung disease following the administration of oestrogens [55] or during pregnancy [56], and the presence of oestrogen receptors and progesterone receptors in LAM cells and angiomyolipomas $[14,57,58]$. Decline in lung function is greater in pre-menopausal women than in post-menopausal women [59].

Oestrogen promotes the proliferation of Tsc-null rat ELT3 leiomyoma-derived cells in vitro [60]. In experimental animals, oestradiol has been shown to stimulate growth of human angiomyolipoma TSC2 ${ }^{+/-}$ cells, which was associated with activation of p42/44 MAPK [61]. Oestrogen has been shown to promote the survival and pulmonary metastasis of Tsc2 ${ }^{-1-}$ ELT3 cells in mice, which was associated with activation of MAPK and inhibited by the MAPK/ERK kinase (MEK) inhibitor CI-1040 [62]. More recently, it has been found that oestrogen stimulates a strong and biphasic activation of ERK2 and transcription of the late response-gene Fra1, which is involved in the oestrogen-stimulated invasive phenotype of LAM patient-derived cells [63]. Activated TORC1/S6K1 signalling enhances the efficiency of translation of Fra1 mRNA regulated by the oestrogen-ERK2 pathway. These results demonstrate integrated signalling of mTOR and oestrogen-ERK pathways in promoting migration and invasion by these cells, and suggest a rationale for a potential combination therapy [63].

Moreover, in lung-derived cells from an explant from a LAM patient, MMP-2 activity was increased by oestrogen receptors, promoting cell invasiveness, and doxycycline, an antibiotic with anti-MMP activity, inhibited this effect. These findings suggest an oestrogen-MMP-driven process involved in lung destruction and LAM cell metastasis [64].

\section{LAM: a neoplasm}

LAM was first defined as a "tumour-like" lesion by the World Health Organization classification of lung tumours in 1999 [65]. Subsequently, LAM has been included among the "perivascular epithelioid cell tumours". These are mesenchymal tumours composed of histologically and immunohistochemically distinctive perivascular epithelioid cells, which present a distinct immunophenotypic profile, with the coexpression of myogenic and melanocytic markers, such as gp100 (a protein recognised by the HMB-45 monoclonal antibody), Melan-A/Mart1, MiTF, $\alpha$-smooth muscle actin and, less often, desmin [66]. Several genetic and cellular findings have shown that LAM cells exhibit the features and behaviours of a neoplasm [67]. The evidence of loss of heterozygosity for TSC genes in the lung, kidney and lymphatic lesions of patients with LAM is consistent with a tumour suppressor gene. Moreover, identical TSC mutations found in the angiomyolipomas, lymph nodes and lungs from the same patients are consistent with seeding from a common source [29]. Recurrence of recipient LAM cells in transplanted lungs, and the presence of LAM cells in the blood and other body fluids suggest that LAM cells exhibit metastatic behaviour [24-27]. However, the source of LAM cells has not been identified. Angiomyolipomas, the uterus and the lymphatic system have been considered as possible sources. The TSC mutations that occur in LAM result in inappropriate, constitutive signalling through the mTOR pathway, which controls protein translation and is activated in human cancers [68]. Inappropriate proliferation and invasion, angiogenesis and lymphangiogenesis, and protease-driven matrix degradation are other features that LAM shares with neoplastic processes [1, 46, 69-71].

Even given the absence of atypia, the low grade proliferation, the questions regarding LAM cell origin and the psychological concerns of patients about such a label, currently, LAM should be considered a chronic neoplastic disease. 


\section{Clinical presentation, natural history and prognosis}

Most of the early clinical conclusions about LAM were based on case reports. Subsequently, clinical papers based on larger numbers of patients appeared, drawing a new and more complete clinical picture of the disease. Data from clinical studies during the past decade have revealed quite different clinical phenotypes $[1,5,72]$. Although the average age at LAM diagnosis in multiple series is $~ 35$ years [73], LAM was found to occur not only in childbearing women but also in those of post-menopausal age, and the life expectancy of patients can span decades $[1,74]$. A large survey $(n=328)$, based on data collected from patients in the database of the US LAM Foundation and LAM Action in the UK, found that more women over the age of 40 years were being diagnosed with LAM, with the result that the mean age at diagnosis was increasing over time [75]. At diagnosis, women with TSC-LAM are younger and have less impaired lung function compared with those with sporadic disease $[5,73]$. The average time from the onset of symptoms related to LAM to the definitive diagnosis of the disease ranges from 2 to 6 years $[5,75]$.

The most common respiratory symptoms at presentation are dyspnoea (over 70\%), pneumothorax ( 50\%), which is often recurrent, and chylous pleural effusions $[5,76,77]$. On CT scans, the characteristic pulmonary abnormalities are well circumscribed, round and thin-walled cysts that are scattered in a bilateral, roughly symmetric pattern, without any lobar predominance (figs 1 and 2). Extrapulmonary presentations are intra-abdominal haemorrhage or the finding of an abdominal mass due to lymphadenopathy, lymphangioleiomyoma and/or angiomyolipoma [5, 74, 78, 79]. Lymphangioleiomyomas are cystic tumours occurring primarily in the abdomen, retroperitoneum and pelvis, and can been found in up to $10 \%$ of patients [72]. They have a distinctive radiological appearance and may change in size during the day [79, 80]. Lymphangioleiomyomas may be asymptomatic or present with nausea, abdominal distension or pain, peripheral oedema, urinary symptoms, or as an acute abdomen [80-82]. Angiomyolipomas are benign tumours that occur mainly in the kidneys (fig. 3). Data from recent studies indicate angiomyolipomas occur in up to $100 \%$ of patients with TSC-LAM and in up to $50 \%$ of those with sporadic LAM [5, 12, 83, 84]. Angiomyolipomas are often asymptomatic, but larger tumours can cause bleeding, which has been treated with selective embolisation or surgery [85]. Patients with TSC commonly have multiple and large angiomyolipomas. Previous series suggested that angiomyolipomas in TSC grow more rapidly and are more prone to complications than angiomyolipomas in patients without TSC [86-88]. According to the International Tuberous Sclerosis Complex Consensus Conference, in patients with TSC, the progression of angiomyolipoma should be assessed every 1-3 years by magnetic resonance imaging of the abdomen, and intervention is recommended for asymptomatic tumours larger than $3 \mathrm{~cm}$ [89]. ERS guidelines on LAM recommend screening for angiomyolipomas in all patients with LAM or suspected LAM, and suggest that asymptomatic renal angiomyolipomas smaller than $4 \mathrm{~cm}$ should be followed by yearly ultrasound, while tumours larger than $4 \mathrm{~cm}$ or with renal aneurysms $>5 \mathrm{~mm}$ in diameter should be checked twice yearly and considered for treatment because of the higher risk of complications [15].

A recent study in a large cohort of patients with sporadic LAM $(n=53)$ showed that angiomylipomas are prone to growth and haemorrhage, present at any time during the clinical course, and tumour presence cannot be predicted by functional parameters or other clinical characteristics such as age at respiratory presentation [83]. No significant difference in the incidence of bleeding or the need for intervention was found between patients with and without TSC. The mean rate of growth for an angiomyolipoma in sporadic LAM was $1.8 \mathrm{~mm}$ per year. Although no overall relationship between tumour size and growth was shown, there was a trend toward larger tumours growing more rapidly [83]. Despite some limitations, due to the retrospective nature of some data, the use of some surrogate end-points such as referral for an intervention and the use of different imaging modalities, the study by $\mathrm{YEOH}$ et al. [83] suggests that angiomyolipomas in sporadic LAM have a similar risk of bleeding to those with TSC and require adequate
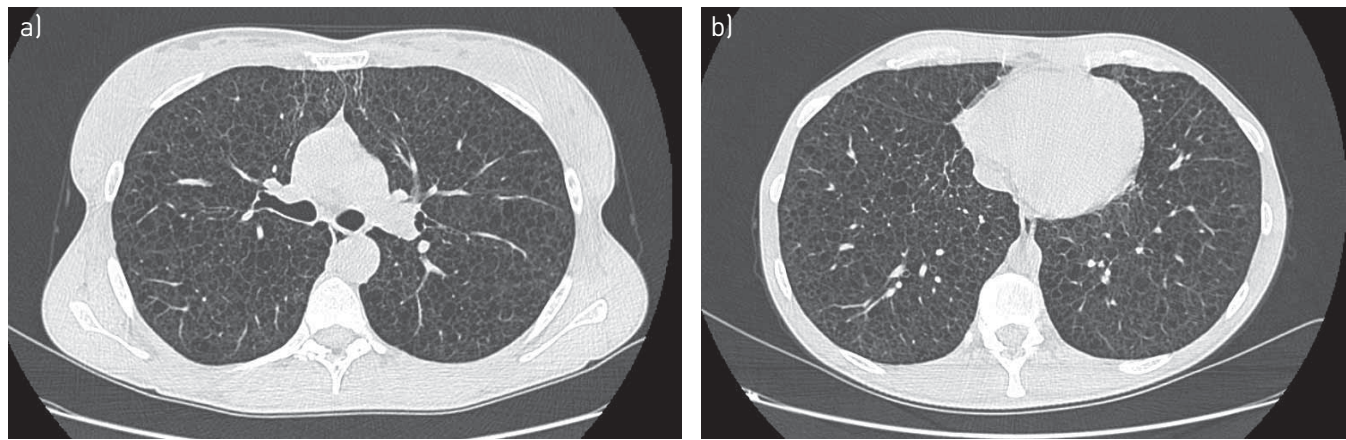

FIGURE 1 a, b) High-resolution chest computed tomography images of a patient with lymphangioleiomyomatosis, showing round-shaped, thin-walled cysts distributed diffusely throughout the lungs. 

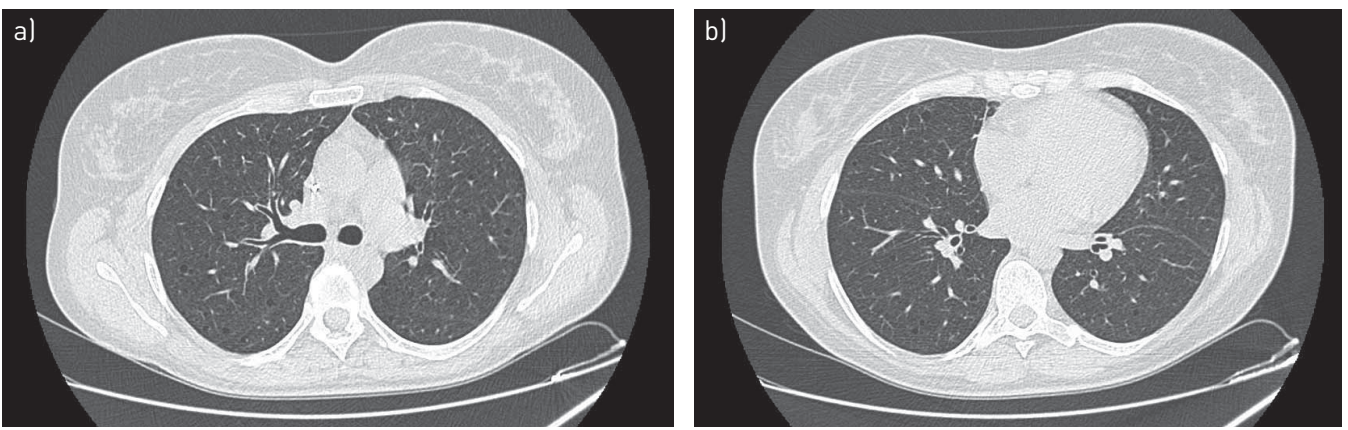

FIGURE 2 a, b) High-resolution chest computed tomography images of a patient with biopsy-proven lymphangioleiomyomatosis, showing a few bilateral, round-shaped, thin-walled cysts.

screening and a closer follow-up than previously suggested by ERS guidelines. The authors propose that imaging should be performed every 12 months for tumours between 11 and $30 \mathrm{~mm}$ in diameter, and every 6 months for tumours $>30 \mathrm{~mm}$. In the latter situation a therapeutic intervention should be considered.

Irrespective of tumour size, the presence of bleeding or the suspicion of a malignancy requires intervention $[15,85,89]$. Embolisation or nephron-sparing surgery can be performed in symptomatic or bleeding tumours depending upon local expertise; nephrectomy should be avoided because of the high incidence of complications and increased risk of future renal insufficiency [15, 89]. A biopsy and, eventually, a conservative surgical intervention are necessary when a malignant lesion is suspected $[15,89]$.

The most frequent pulmonary function abnormalities in LAM are airflow obstruction and decreased lung diffusion capacity $[5,90,91]$. $\sim 30 \%$ of patients have normal tests. Airflow obstruction is present in over $60 \%$ of patients and reduced diffusing capacity can be seen in up to $80 \%$ of patients $[5,90,92]$. Airflow

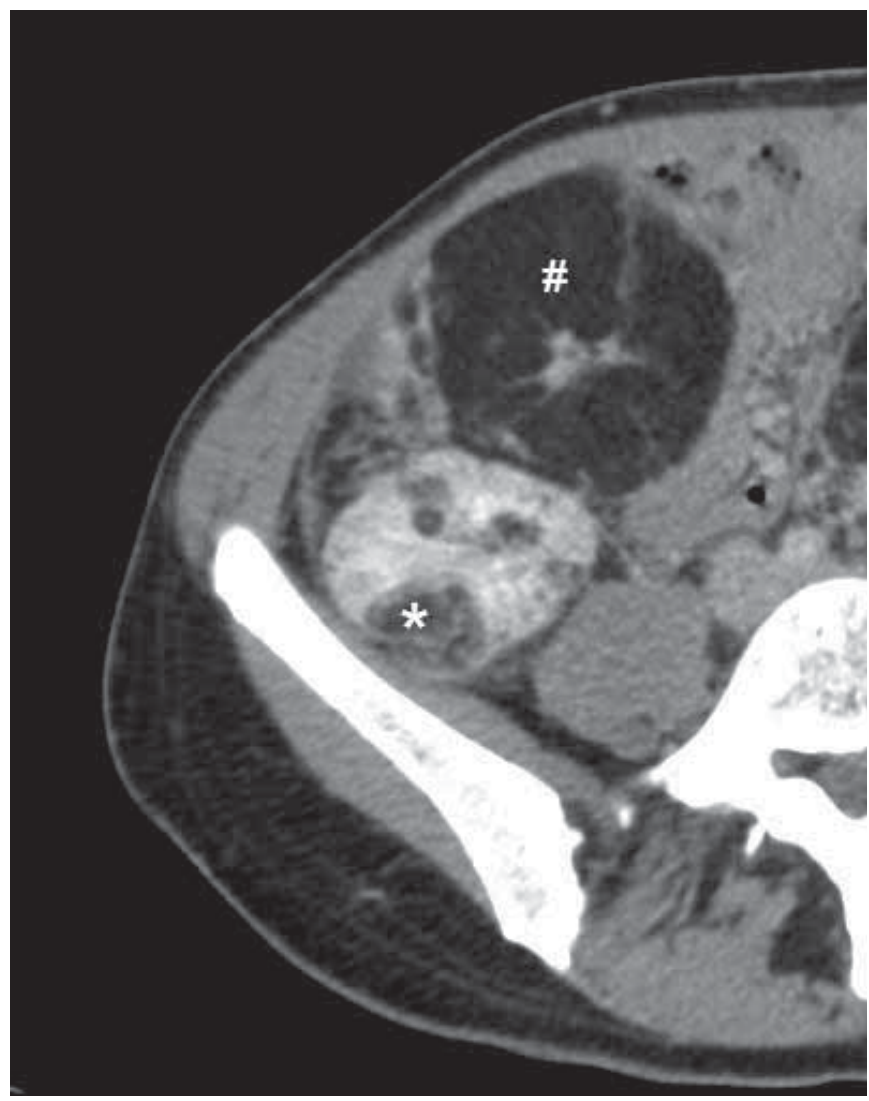

FIGURE 3 Abdominal contrast-enhanced computed tomography image of a patient with tuberous sclerosis complex-lymphangioleiomyomatosis, showing multiple intracortical (white asterisk) and one extracortical (white hash) right renal angiomyolipomas with a fatty, low-density component. 
obstruction is reversible in $25-30 \%$ of LAM patients [90, 93]. Diffusing capacity of the lung for carbon monoxide (DLCO) and forced expiratory volume in $1 \mathrm{~s}$ (FEV1) have been shown to correlate with disease severity as assessed by CT, LAM histology score and exercise testing [59, 91, 94-96].

The annual decline in lung function in untreated patients is variable. Mean annual decline in FEV 1 has been reported as $60-120 \mathrm{~mL}$ per year in different retrospective studies of referral centres or national cohorts [1, 97, 98]. Two recent clinical trials about use of sirolimus and doxycycline showed a mean $\triangle$ FEV1 post-bronchodilator in the placebo group of $-134 \mathrm{~mL}$ (in the 12 month study period) and $-90.3 \mathrm{~mL}$ per year, respectively [99, 100].

Prognostic information in LAM has changed over time. Early retrospective studies based on small numbers reported a 5- and 10-year mortality of 40 and $80 \%$, respectively [101, 102]. More recent studies showed that LAM has a slower progression and a better prognosis than previously thought, even if the disease course varies widely in individual patients. Mortality at 10 years has been estimated to be $30 \%$ from the time of lung biopsy [94] and $\sim 10-20 \%$ from the onset of symptoms $[1,74,94]$. Recently, in a large cohort of patients $(n=401)$ with long-term follow-up [103], an estimated 10-year transplant-free survival of $86 \%$ was observed; the median transplant-free survival for the overall cohort was 29 years from the time of onset of symptoms, and 23 years from the time of diagnosis. No statistically significant difference between the hormonally treated and untreated subgroup was found when adjusted for the severity of disease (i.e. oxygen use). Even if the results may be biased by the lack of data from pulmonary function tests, the conclusions of the study about survival are consistent with estimates from previous recent cohorts [103]. Although LAM has a heterogeneous course and often unpredictable outcome, in the past few years some clinical characteristics have been found to be associated with prognosis. Previously it was found that obstructive functional abnormalities, as measured by reduction in the $\mathrm{FEV}_{1} /$ forced vital capacity (FVC) ratio and hyperinflation, manifested as an increase in total lung capacity at presentation, and were associated with a worse prognosis and reduced survival [104]. A subsequent study on a larger cohort of patients with LAM analysed predictors of decline in pulmonary function tests for a mean duration of 5 years [59]. Initial lung function and age were found to predict functional decline. The rate of decline in FEV1 was inversely correlated with the initial DLCO and age: rates of decline in FEV1 were lower in older patients and in patients with higher DLCO and FEV1. Patients with reversible obstruction to bronchodilators appeared to have a greater predominance of proliferative lung lesions [59], and bronchodilator responsive airflow obstruction has been associated with an accelerated decline in lung function [92]. A report from Japan suggests that presentation with pneumothorax is associated with younger age and a more favourable prognosis than presentation with dyspnoea (10-year survival rate of $89 \%$ and $47 \%$, respectively) [91]. In accordance with these results, the recent study by Oprescu et al. [103] showed that patients who presented with dyspnoea or cough had a worse prognosis compared with the subgroup who presented with pleural disease (pneumothorax or pleural effusion) or other presentations. In this report, age at presentation, the need for supplemental oxygen therapy and reported weight loss were independent predictors of survival; older age at presentation was associated with improved survival, whereas the need for supplemental oxygen therapy and reported weight loss were associated with a shorter survival. The authors suggest that the mechanism for the association between weight loss and worse prognosis might follow the model established for chronic obstructive pulmonary disease [105]. Table 1 summarises the prognostic factors.

\section{Biomarkers of LAM}

Vascular endothelial growth factor-D

Vascular endothelial growth factor-D (VEGF-D) is a lymphangiogenic growth factor that induces formation of lymphatics and promotes the spread of tumour cells to lymph nodes. Serum levels of

TABLE 1 Prognostic clinical characteristics in lymphangioleiomyomatosis

\section{Worse prognosis}

Dyspnoea as presenting feature

Weight loss

Supplemental oxygen therapy

Reversible airflow obstruction

High VEGF-D

Better prognosis

Pneumothorax as presenting feature

Older age at diagnosis

Higher FEV1, DLCO at diagnosis

VEGF-D: vascular endothelial growth factor-D; FEV1: forced expiratory volume in 1s; DLco: diffusing capacity of the lung for carbon monoxide. 
VEGF-D have been shown to be elevated in patients with sporadic LAM as compared with healthy controls, and higher levels of serum VEGF-D were associated with greater loss of pulmonary function as measured by DLCO/alveolar volume and FEV1/FVC, all suggesting that VEGF-D influences lymphangiogenesis in LAM [106].

Young et al. [107] first reported that serum VEGF-D levels were higher in LAM than in similar cystic or chylous lung diseases, indicating that it might be a clinically useful diagnostic test for differential diagnosis. A subsequent study by GLASGOw et al. [108], comparing VEGF-D levels in patients with sporadic LAM $(\mathrm{n}=111)$ to those in healthy volunteers, confirmed that serum VEGF-D levels were higher in patients with LAM. However, when patient samples were grouped based on the extent of lymphatic extrapulmonary involvement (e.g. lymphangioleiomyomas or adenopathy) the difference was maintained only for patients with LAM and lymphatic involvement. In this subgroup of patients, higher VEGF-D levels were associated with a higher severity score on CT scan analysis and lower DLCO. These results suggest that VEGF-D levels might be a measure of lymphatic involvement in LAM [108].

The validity of serum VEGF-D levels as a diagnostic test was confirmed in a prospective study showing that a serum VEGF-D level higher than $800 \mathrm{pg} \cdot \mathrm{mL}^{-1}$ in a woman with typical changes on high-resolution CT is diagnostically specific for LAM, reducing the need for lung biopsy, and is associated with pulmonary LAM in women with TSC [109]. The study did not show a relationship between serum VEGF-D levels and the use of supplemental oxygen or FEV1 in the group of patients with LAM. In this study, pulmonary function testing was not performed at the same time as the determination of VEGF-D. Serum VEGF-D levels higher than $800 \mathrm{pg} \cdot \mathrm{mL}^{-1}$ plus findings of compatible cystic change on high-resolution CT were considered as diagnostic in defining the inclusion criteria for the Multicenter International Lymphangioleiomyomatosis Efficacy of Sirolimus (MILES) trial [99].

Recently, the results of an analysis of data from the MILES trial to assess the usefulness of serum VEGF-D levels as a marker of severity and therapeutic response showed that VEGF-D levels at baseline were higher in patients who needed supplemental oxygen and in those who used a bronchodilator [110]. Moreover, baseline VEGF-D levels were associated with markers of airflow obstruction and hyperinflation. Median serum VEGF-D concentrations fell significantly from baseline at 6 and 12 months in the sirolimus group but remained almost stable in the placebo group. In addition, in the sirolimus group each one-unit increase in baseline $\log (\mathrm{VEGF}-\mathrm{D})$ was associated with a $5 \mathrm{~mL}$ per month increase in FEV1 and a $14 \mathrm{~mL}$ per month increase in FVC. These results confirm that VEGF-D is a useful biomarker that correlates with disease severity and treatment response. In addition, the results suggested that serum VEGF-D concentrations might also be useful for stratification of patients for trials and reduce the number of patients needed to adequately power studies.

The mechanisms by which VEGF-D might affect disease severity in LAM is, as yet, unknown. LAM nodules are known to contain VEGF-D. LAM cells might disseminate via lymphangiogenesis-mediated shedding of LAM cell clusters, a process that might result in the development of new lesions in the lung and elsewhere $[67,111]$.

\section{Other biomarkers}

MMPs are components of the extracellular matrix involved in lung remodelling and lymphangiogenesis [112]. MMPs have also been associated with LAM lesions, and LAM nodules have been shown to contain MMP activators and inhibitors [42, 113-115]. Levels of tissue inhibitor of metalloproteinase-3, which inhibits some MMPs, are low in LAM lesions compared with normal lung parenchyma, which may facilitate MMP-catalysed proteolysis [114]. Serum levels of MMP-9 are higher in patients with LAM than in normal subjects, suggesting that excessive production of MMPs by LAM cells may contribute to lung destruction [47].

Monitoring of urinary MMPs in LAM could be of value in assessing disease severity and response to therapeutic agents. Urinary levels of MMPs were reported to become undetectable after 3 months of treatment with doxycycline, an inhibitor of MMPs, in a patient with severe LAM [116]. Moreover, there was a significant reduction in urinary MMP-9 levels and serum MMP-2 levels following treatment with doxycycline in an open-label, single-arm, interventional clinical trial [117].

\section{Treatment}

\section{Hormonal treatment}

In the past, various hormonal strategies have been used in the treatment of LAM. Effects of bilateral oophorectomy are controversial, and there is no objective evidence of improvement with anti-oestrogen therapy $[118,119]$. Improvement following use of gonadotrophin-releasing hormone $(\mathrm{GnRH})$ analogues has been reported, but other studies were inconclusive and no controlled clinical trials on $\mathrm{GnRH}$ analogues have been conducted [120-123]. Although progesterone became the standard of care after a 
series of case reports and clinical studies [124, 125], there are no clinical trials of its use in LAM. Retrospective studies have shown dissimilar results. JoHNSON and TATTERSFIELD [97] found a significant reduction in the rate of decline of DLCO in patients treated with progesterone compared with untreated patients. Another retrospective study of a large cohort of patients with LAM $(n=275)$ showed no difference in the overall yearly rates of decline of FEV 1 and DLCO between patients who were treated with oral or intramuscular progesterone and patients who did not receive progesterone [59]. Because of the inconclusive results and the lack of controlled clinical trials, at the moment, hormonal treatment in patients with LAM should be discouraged.

\section{mTOR inhibitors}

The mTOR inhibitors, sirolimus (also known as rapamycin) and everolimus, block mTOR-mediated activation of downstream kinases, inhibiting proliferation and growth of LAM cells $[34,126]$.

Inhibitors of mTOR have been proven to be effective in the treatment of patients with LAM and TSC. The Cincinnati Angiomyolipoma Sirolimus Trial (CAST) was a pilot study that showed a significant reduction of angiomyolipoma volume after 1 year of treatment with sirolimus and an increase in functional parameters in the subgroup of patients with LAM [127].

The MILES trial, a larger randomised placebo-controlled trial on the safety and efficacy of sirolimus in patients with LAM and moderate functional impairment, showed a stabilisation of lung function, expressed as FEV1, during the 12-month treatment period [99]. After discontinuation of treatment, the decline in lung function resumed in the sirolimus group and paralleled that in the placebo group. Moreover, during the treatment period, the sirolimus group showed improvement from baseline to 12 months in measures of FVC, quality of life and serum VEGF-D. No difference was found in 6-min walking distance (6MWD) and DLCO between the two groups [99]. During the treatment period, the serum level of sirolimus was maintained between 5 and $15 \mathrm{ng} \cdot \mathrm{mL}^{-1}$. Sirolimus was associated with an increased frequency of adverse events, of which the most common were mucositis, gastrointestinal events, hypercholesterolaemia, acneiform rash and swelling in the lower extremities. However, the rates of serious adverse events were similar in the two study groups.

Patients with chylous effusions were not included in the MILES trial because of the potential effects on pulmonary function. An observational study of patients with rapidly progressive LAM and chylous complications showed that therapy with sirolimus was also associated with a reduction in the size of chylous effusions and lymphangioleiomyomas, leading to almost complete resolution of these conditions [128]. A case of resolution of lung infiltrates on CT scan, with improvement in symptoms and functional parameters, and resolution of respiratory failure after treatment with sirolimus has been reported in a woman with LAM who had already undergone bilateral pleurodesis [129]. The authors concluded that decreased LAM lesions along the thoracic duct led to partial relief of the obstruction, with improved chyle flow and decreased leakage into the lung. Reduction in the size of lung nodules and LAM cell infiltrates involving or surrounding the airways probably accounts for the stabilisation or improvement in lung function associated with sirolimus therapy.

Drug toxicity and development of resistance are potential problems related to therapy with mTOR inhibitors. Recently, YAO et al. [130] published the results of a study on the effects of sustained treatment with sirolimus, in a cohort of 38 patients with LAM, including patients with lymphatic involvement. Treatment with sirolimus for a period of $\sim 3.5$ years stabilised lung function by slowing declines in FEV1 and DLCO and changes in lung volume occupied by cysts. No evidence of worsening was seen in terms of exercise tolerance or exercise capacity [130]. In a subgroup of 12 patients followed for $\sim 5$ years, the study showed both a reduction in functional decline and changes in cyst size. The prevalence of adverse events associated with sirolimus was high; however, most patients were able to continue therapy with only brief interruptions [130]. Although the high number of patients with lymphatic involvement in this cohort may not be representative of the entire LAM population, these results suggest that the therapeutic effects of sirolimus on functional decline and cystic changes are sustained over time with a manageable and acceptable spectrum of toxicities, at least in the population of patients who are likely to need therapeutic intervention.

Another current concern about LAM therapy is whether lower doses of sirolimus could be used to maintain therapeutic effects and reduce toxicity. A Japanese retrospective, observational study of 15 patients with LAM before and after therapy with serum levels of sirolimus $<5 \mathrm{ng} \cdot \mathrm{mL}^{-1}$ throughout the treatment period showed an improvement in the annual rate of change in FVC and FEV1 in the eight patients without chylous effusions. All but one of the remaining seven patients with chylous effusions experienced complete resolution of chylothorax and significant reduction of chylous ascites [131]. Except for a patient who developed a slight increase in parenchymal opacity on chest radiography and a patient who developed Aspergillus infection, the adverse events were mostly low grade. Despite the low-dose regimen, the incidence 
of adverse events was similar to that reported previously. Only hypercholesterolaemia was not observed in the study. This result may be explained by the Asian study population, as suggested by a previous subgroup analysis of the MILES trial [132] showing different adverse events between American and Japanese participants. Although the retrospective, non-controlled design of the study does not allow definitive conclusions, the results suggest that even at a blood trough level of $<5 \mathrm{ng} \cdot \mathrm{mL}^{-1}$, sirolimus might be clinically effective and safe. Prospective studies comparing conventional and low-dose sirolimus are necessary.

Everolimus is a second generation mTOR1 inhibitor, which has been proven to be effective in reducing the size of giant cell astrocytomas in patients with TSC $[133,134]$. Recently, the EXIST-2 trial proved the efficacy of everolimus in decreasing the size of renal angiomyolipomas in patients with TSC or LAM [135]. In addition, patients on everolimus had a significantly higher skin lesion response rate than patients on placebo. Adverse events were consistent with the known everolimus safety profile. Stomatitis, nasopharyngitis, acne-like skin lesions, headache, cough and hypercholesterolaemia were the most common adverse events. Infection occurred in $65 \%$ of patients on everolimus without grade 4 infectious events. The results of an exploratory, open-label, non-randomised, within-subject dose escalation trial of everolimus in patients with LAM have just been published [136]. Primary end-points were safety and tolerability, pharmacokinetics, and VEGF-D levels; secondary end-points were measures of lung function. 24 females with sporadic or TSC-LAM were enrolled in four different centres. Patients received everolimus at $2.5 \mathrm{mg} \cdot \mathrm{day}^{-1}$ for 4 weeks, followed by dose titration to $5 \mathrm{mg} \cdot \mathrm{day}^{-1}$ for 4 weeks then $10 \mathrm{mg} \cdot \mathrm{day}^{-1}$ for 18 weeks. The safety profile of everolimus appeared similar to that of sirolimus in the MILES trial. The most common adverse events were stomatitis and headache; other common adverse events were peripheral oedema, diarrhoea, nausea, cough, oropharyngeal pain and fatigue. Four serious adverse events felt to be related to the study drug were observed including pneumonia, pneumocystis and heart failure, which were not observed in the MILES trial. VEGF-D levels decreased throughout the treatment period with most of the reduction occurring within the first 8 weeks. Stability of FVC and improvement in FEV1, relative to baseline, were found and a trend toward improvement in exercise capacity, as measured by increase in 6MWD from baseline, was observed. The efficacy results after 26 weeks of treatment were compared with the 6-month data in the placebo-controlled group from the MILES study showing a slightly larger increase in FEV1 and a lower improvement in FVC than the absolute difference seen between sirolimus and placebo in the MILES study. However, a difference between the patient populations including a greater number of Asian patients and a greater severity of disease in the MILES placebo group may affect the comparison [136].

Currently, therapy with mTOR inhibitors in LAM is indicated in patients with abnormal lung function, patients whose lung function is declining rapidly, and/or for the treatment of chylous effusions, large angiomyolipomas and lymphangioleiomyomas (figs 4 and 5). The role of sirolimus in patients with normal or stable lung function is unclear.

\section{Future treatments}

Although mTOR inhibitors are effective in stabilising lung function, reducing the size of angiomyolipomas and controlling lymphatic complications, they are not curative, and the benefits are observed only during

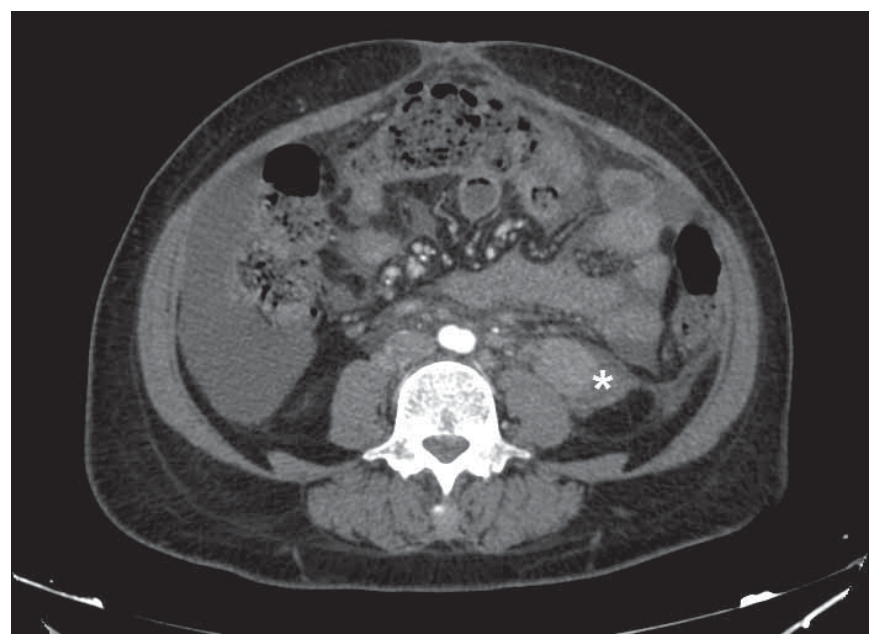

FIGURE 4 Abdominal contrast- enhanced computed tomography image of a 39-year-old patient with a biopsy-proven lymphangioleiomyoma and chylous ascites needing drainage. The lymphangioleiomyoma is evident as a solid, paraortic, retroperitoneal mass, showing enhancement and low density, intra-lesion area (white asterisk). 

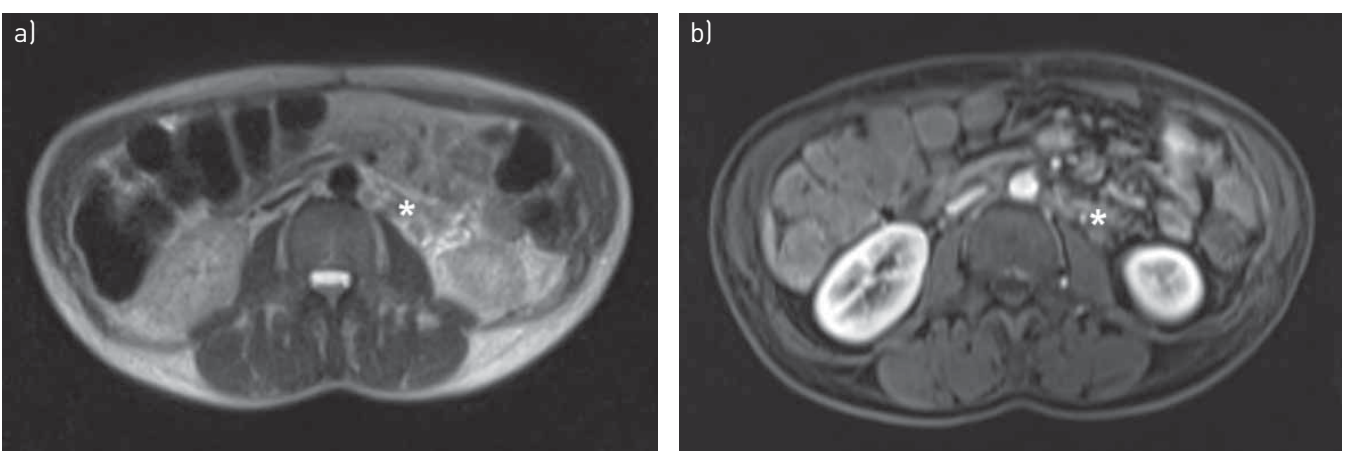

FIGURE 5 Abdominal magnetic resonance imaging of the same patient after 3 months of therapy with sirolimus, showing complete resolution of the effusion and an initial volume reduction of the lymphangioleiomyomas (white asterisk) in T2-weighted images (a) and T1-weighted contrast-enhanced fat-suppressed images (b).

the treatment period, with regain of disease-related symptoms and complications after cessation of therapy. Recent advances in understanding the molecular pathogenesis of the disease have suggested new potential targets for treatment of LAM.

Autophagy has recently been shown to be a critical component of TSC tumorigenesis. The combination of mTORC1 and autophagy inhibition (using sirolimus and chloroquine) is more effective than either treatment alone in inhibiting the survival of tuberin (TSC2)-null cells, growth of TSC2-null xenograft tumours and the development of spontaneous renal tumours in $\mathrm{Tsc}^{+/-}$mice [43]. Thus, dual inhibition of mTORC1 and autophagy is a potential therapeutic strategy for patients with TSC and LAM. A phase 1 clinical trial on safety of the combined use of sirolimus and hydroxychloroquine in patients with LAM is ongoing (Elizabeth Henske, Brigham and Women's Hospital, Boston, MA, USA; personal communication).

As previously mentioned, MMPs are involved in pathogenesis of the disease. Thus, inhibition of MMPs is considered a potential target in treatment of LAM. After the report of a case of significant clinical improvement in association with a reduction of urinary MMPs after treatment with doxycycline by Moses et al. [116], the drug has been tested in an open label interventional study. 31 patients completed 12 months of treatment showing a significant mean decrease in FEV1 $(70 \mathrm{~mL})$, but no significant variation in DLCO and 6MWD, and a significant reduction in urinary MMP-9 levels and serum MMP-2 levels but no significant differences between pre- and post-treatment serum MMP-9 levels, suggesting a mechanism of action different from MMP blockade [116]. In a double-blind, placebo-controlled clinical trial of doxycycline, the mean decline in FEV1 per year did not differ between the placebo and the treatment group, although the effect of doxycycline on urinary levels of MMP-9 was confirmed [100]. The results of this study may have been limited by the small number of patients $(n=15)$ who completed the 24 months of treatment, due to a high percentage of withdrawals. Nonetheless, the authors conclude that the lack of effect of the drug on any clinical outcome (FEV1, FVC, DLCO, total lung capacity, shuttle-walk distance or quality of life scores) makes it unlikely that doxycycline has a useful effect in LAM.

Statins inhibit 3-hydroxy-3-methylglutaryl-coenzyme and thereby block geranylgeranylation of Rho GTPases and farnesylation of Ras and Rheb [137]. Simvastatin was shown to inhibit RhoA GTPase activity and proliferation of TSC-null cells and TSC2-null tumour growth in mice, and to promote apoptosis [49]. Treatment with sirolimus and simvastatin prevented recurrence of the tumours, even after discontinuation of both drugs [49]. By contrast, atorvastatin failed to reduce the size of liver and renal tumours in a mouse model of TSC [138]. In a mouse model of LAM, simvastatin prevented alveolar space enlargement and, together with sirolimus, blocked MMP upregulation and alveolar destruction [139]. The use of different cell types may explain the contradictory evidence regarding the efficacy of statins in these preclinical models. Recently, the use of these drugs on the same TSC-null cells, showed the growth-inhibitory and proapoptotic effects of simvastatin compared with atorvastatin [140]. A retrospective review of 335 patients with LAM showed a significantly greater yearly rate of decline of DLCO \% predicted in LAM patients on statins in comparison with their matched controls [141]. However, in this study, the number of patients on simvastatin was small and the patients were not given an mTOR inhibitor. The results of a retrospective analysis of patients who were treated with sirolimus alone, or a combination of sirolimus and simvastatin, or simvastatin alone because of hypercholesterolaemia have just been published [142]. Within the limitations of the study design, combined therapy with sirolimus plus simvastatin did not result in a greater prevalence of adverse events beyond those expected from the use of each one of the two drugs and simvastatin did not seem to modify the beneficial effects of sirolimus therapy in LAM [142]. A phase 1-2 clinical trial on combination 
therapy with mTOR inhibitors (everolimus and sirolimus) and simvastatin is currently underway (Vera Krymskaya, University of Pennsylvania, Philadelphia, PA, USA; personal communication).

As a role for oestrogens in molecular pathogenesis of LAM has been postulated, therapeutic strategies including anti-oestrogen therapy represent a future possibility. A potential new therapeutic approach consists of suppressing oestrogen secretion with aromatase inhibitors, especially in post-menopausal women in whom the adrenal glands are the main source of oestrogens [143]. Letrozole is an aromatase inhibitor currently used to treat oestrogen receptor-positive breast cancer. A trial of aromatase inhibition in LAM (TRAIL) is being conducted (Francis X. McCormack, University of Cincinnati, Cincinnati, OH, USA; personal communication).

Recently, an integration of the mTOR and E2-ERK pathways in the pathogenesis of LAM has been seen [63]. Combination therapy targeting the E2-ERK pathway and the mTORC1 pathway, for example using an oestrogen receptor antagonist in combination with mTOR inhibition, may be effective for LAM.

It has been demonstrated that platelet-derived growth factor receptor $\beta$ (PDGFR $\beta$ ) is present and active in human and murine TSC lesions [144, 145]. An inverse relationship between mTOR activation and PDGFR $\beta$ levels in TSC-derived cells has also been shown [146]. In a preclinical model, nearly complete tumour inhibition with a combination of rapamycin and imatinib targeting two distinct signalling pathways (mTORC1 and PDGFR $\beta$, respectively) has been observed, suggesting a rationale for the clinical use of this combination therapy for TSC and LAM [147].

In recent decades great progress has been made, drawing a new picture of LAM, however, more efforts are still needed to eliminate the disease. Challenging issues for the future include a better comprehension of pathogenesis, including both canonical and non-canonical pathways and the role of oestrogen, and the development of new biomarkers and new therapeutic approaches. A combination strategy targeting different pathways represents a promising approach for management of this disease.

\section{References}

1 Urban T, Lazor R, Lacronique J, et al. Pulmonary lymphangioleiomyomatosis. A study of 69 patients. Groupe d'Etudes et de Recherche sur les Maladies "Orphelines" Pulmonaires (GERM“O”P). Medicine (Baltimore) 1999; 78: 321-337.

2 Harari S, Torre O, Moss J. Lymphangioleiomyomatosis: what do we know and what are we looking for? Eur Respir Rev 2011; 20: 34-44.

3 Franz DN, Brody A, Meyer C, et al. Mutational and radiographic analysis of pulmonary disease consistent with lymphangioleiomyomatosis and micronodular pneumocyte hyperplasia in women with tuberous sclerosis. Am J Respir Crit Care Med 2001; 164: 661-668.

4 The European Chromosome 16 Tuberous Sclerosis Consortium. Identification and characterization of the tuberous sclerosis gene on chromosome 16. Cell 1993; 75: 1305-1315.

5 Ryu JH, Moss J, Beck GJ, et al. The NHLBI lymphangioleiomyomatosis registry: characteristics of 230 patients at enrollment. Am J Respir Crit Care Med 2006; 173: 105-111.

6 Aubry MC, Myers JL, Ryu JH, et al. Pulmonary lymphangioleiomyomatosis in a man. Am J Respir Crit Care Med 2000; 162: 749-752.

7 Schiavina M, Di Scioscio V, Contini P, et al. Pulmonary lymphangioleiomyomatosis in a karyotypically normal man without tuberous sclerosis complex. Am J Respir Crit Care Med 2007; 176: 96-98.

8 Adriaensen ME, Schaefer-Prokop CM, Duyndam DA et al. Radiological evidence of lymphangioleiomyomatosis in female and male patients with tuberous sclerosis complex. Clin Radiol 2011; 66: 625-628.

9 Ryu JH, Sykes AM, Lee AS, et al. Cystic lung disease is not uncommon in men with tuberous sclerosis complex. Respir Med 2012; 106: 1586-1590.

10 Costello LC, Hartman TE, Ryu JH. High frequency of pulmonary lymphangioleiomyomatosis in women with tuberous sclerosis complex. Mayo Clin Proc 2000; 75: 591-594.

11 Moss J, Avila NA, Barnes PM, et al. Prevalence and clinical characteristics of lymphangioleiomyomatosis (LAM) in patients with tuberous sclerosis complex. Am J Respir Crit Care Med 2001; 164: 669-671.

12 Cudzilo CJ, Szczesniak RD, Brody AS, et al. Lymphangioleiomyomatosis screening in women with tuberous sclerosis. Chest 2013; 144: 578-585.

13 Osborne JP, Fryer A, Webb D. Epidemiology of tuberous sclerosis. Ann NY Acad Sci 1991; 615: 125-127.

14 Harknett EC, Chang WY, Byrnes S, et al. Use of variability in national and regional data to estimate the prevalence of lymphangioleiomyomatosis. QJM 2011; 104: 971-979.

15 Johnson SR, Cordier JF, Lazor R, et al. European Respiratory Society guidelines for the diagnosis and management of lymphangioleiomyomatosis. Eur Respir J 2010; 35: 14-26.

16 Ferrans VJ, Yu ZX, Nelson WK, et al. Lymphangioleiomyomatosis (LAM): a review of clinical and morphological features. J Nippon Med Sch 2000; 67: 311-329.

17 Zhe X, Schuger L. Combined smooth muscle and melanocytic differentiation in lymphangioleiomyomatosis. J Histochem Cytochem 2004; 52: 1537-1542.

18 Ohori NP, Yousem SA, Sonmez-Alpan E, et al. Estrogen and progesterone receptors in lymphangioleiomyomatosis, epithelioid hemangioendothelioma, and sclerosing hemangioma of the lung. Am J Clin Pathol 1991; 96: 529-535.

19 Barberis M, Monti GP, Ziglio G, et al. Oestrogen and progesterone receptors detection in pulmonary lymphangioleiomyomatosis. Am J Respir Crit Care Med 1996; 153: A272.

20 Juvet SC, McCormack FX, Kwiatkowski DJ, et al. Molecular pathogenesis of lymphangioleiomyomatosis: lessons learned from orphans. Am J Respir Cell Mol Biol 2007; 38: 398-408. 
Matsumoto Y, Horiba K, Usuki J, et al. Markers of cell proliferation and expression of melanosomal antigen in lymphangioleiomyomatosis. Am J Respir Cell Mol Biol 1999; 21: 327-336.

Pacheco-Rodriguez G, Steagall WK, Crooks DM, et al. TSC2 loss in lymphangioleiomyomatosis cells correlated with expression of CD44v6, a molecular determinant of metastasis. Cancer Res 2007; 67: 10573-10581.

Hayashi T, Fleming MV, Stetler-Stevenson WG, et al. Immunohistochemical study of matrix metalloproteinases (MMPs) and their tissue inhibitors (TIMPs) in pulmonary lymphangioleiomyomatosis (LAM). Human Pathol 1997; 28: 1071-1078.

Bittmann I, Rolf B, Amann G, et al. Recurrence of lymphangioleiomyomatosis after single lung transplantation: new insights into pathogenesis. Human Pathol 2003; 34: 95-98.

Karbowniczek M, Astrinidis A, Balsara BR, et al. Recurrent lymphangioleiomyomatosis after transplantation: genetic analyses reveal a metastatic mechanism. Am J Respir Crit Care Med 2003; 167: 976-982.

Karbowniczek M, Yu J, Henske EP. Renal angiomyolipomas from patients with sporadic lymphangiomyomatosis contain both neoplastic and non-neoplastic vascular structures. Am J Pathol 2003; 162: 491-500.

Crooks DM, Pacheco-Rodriguez G, DeCastro RM, et al. Molecular and genetic analysis of disseminated neoplastic cells in lymphangioleiomyomatosis. Proc Natl Acad Sci USA 2004; 101: 17462-17467.

Smolarek TA, Wessner LL, McCormack FX, et al. Evidence that lymphangiomyomatosis is caused by TSC2 mutations: chromosome $16 \mathrm{p} 13$ loss of heterozygosity in angiomyolipomas and lymph nodes from women with lymphangiomyomatosis. Am J Hum Genet 1998; 62: 810-815.

Carsillo T, Astrinidis A, Henske EP. Mutations in the tuberous sclerosis complex gene TSC2 are a cause of sporadic pulmonary lymphangioleiomyomatosis. Proc Natl Acad Sci USA 2000; 97: 6085-6090.

Yu J, Astrinidis A, Henske EP. Chromosome 16 loss of heterozygosity in tuberous sclerosis and sporadic lymphangiomyomatosis. Am J Respir Crit Care Med 2001; 164: 1537-1540.

Sato T, Seyama K, Fujii H, et al. Mutational analysis of the TSC1 and TSC2 genes in Japanese patients with pulmonary lymphangioleiomyomatosis. J Hum Genet 2002; 47: 20-28.

Loewith R, Jacinto E, Wullschleger S, et al. Two TOR complexes, only one of which is rapamycin sensitive, have distinct roles in cell growth control. Mol Cell 2002; 10: 457-468.

Sarbassov DD, Ali SM, Kim DH, et al. Rictor, a novel binding partner of mTOR, defines a rapamycin-insensitive and raptor-independent pathway that regulates the cytoskeleton. Curr Biol 2004; 14: 1296-1302.

Castro AF, Rebhun JF, Clark GJ, et al. Rheb binds tuberous sclerosis complex 2 (TSC2) and promotes S6 kinase activation in a rapamycin- and farnesylation-dependent manner. J Biol Chem 2003; 278: 32493-32496.

Tee AR, Manning BD, Roux PP, et al. Tuberous sclerosis complex gene products, tuberin and hamartin, control mTOR signaling by acting as a GTPase-activating protein complex toward Rheb. Curr Biol 2003; 13: 1259-1268.

Zhang Y, Gao X, Saucedo LJ, et al. Rheb is a direct target of the tuberous sclerosis tumour suppressor proteins. Nat Cell Biol 2003; 5: 578-581.

Ma L, Chen Z, Erdjument-Bromage H, et al. Phosphorylation and functional inactivation of TSC2 by Erk implications for tuberous sclerosis and cancer pathogenesis. Cell 2005; 121: 179-193. PRAS40. Nature Cell Biol 2007; 9: 316-323.

Fingar DC, Salama S, Tsou C, et al. Mammalian cell size is controlled by mTOR and its downstream targets S6K1 and 4EBP1/eIF4E. Genes Dev 2002; 16: 1472-1487.

Carriére A, Cargnello M, Julien LA, et al. Oncogenic MAPK signaling stimulates mTORC1 activity by promoting RSK-mediated raptor phosphorylation. Curr Biol 2008; 18: 1269-1277.

Kim J, Kundu M, Viollet B, et al. AMPK and mTOR regulate autophagy through direct phosphorylation of Ulk1. Nat Cell Biol 2011; 13: 132-141.

Ganley IG, Lam du H, Wang J, et al. ULK1.ATG13.FIP200 complex mediates mTOR signaling and is essential for autophagy. J Biol Chem 2009; 284: 12297-12305.

Parkhitko A, Myachina F, Morrison TA, et al. Tumorigenesis in tuberous sclerosis complex is autophagy and p62/sequestosome 1 (SQSTM1)-dependent. Proc Natl Acad Sci USA 2011; 108: 12455-12460.

Goncharova EA, Goncharov DA, Li H, et al. mTORC2 is required for proliferation and survival of TSC2-null cells. Mol Cell Biol 2011; 31: 2484-2498.

Hartman TR, Liu D, Zilfou JT, et al. The tuberous sclerosis proteins regulate formation of the primary cilium via a rapamycin-insensitive and polycystin 1-independent pathway. Hum Mol Genet 2009; 18: 151-163.

Boehlke C, Kotsis F, Patel V, et al. Primary cilia regulate mTORC1 activity and cell size through Lkb1. Nat Cell Biol 2010; 12: 1115-1122.

Lamb RF, Roy C, Diefenbach TJ, et al. The TSC1 tumour suppressor hamartin regulates cell adhesion through ERM proteins and the GTPase Rho. Nat Cell Biol 2000; 2: 281-287.

Karbowniczek M, Robertson GP, Henske EP. Rheb inhibits C-raf activity and B-raf/C-raf heterodimerization. J Biol Chem 2006; 281: 25447-25456.

Neuman NA, Henske EP. Non-canonical functions of the tuberous sclerosis complex-Rheb signaling axis. EMBO Mol Med 2011; 3: 189-200.

Karbowniczek M, Zitserman D, Khabibullin D, et al. The evolutionarily conserved TSC/Rheb pathway activates Notch in tuberous sclerosis complex and Drosophila external sensory organ development. J Clin Invest 2010; 120: 93-102. Huang J, Dibble CC, Matsuzaki M, et al. The TSC1-TSC2 complex is required for proper activation of mTOR complex 2. Mol Cell Biol 2008; 28: 4104-4115.

Lee PS, Tsang SW, Moses MA, et al. Rapamycin-insensitive up-regulation of MMP2 and other genes in tuberous sclerosis complex 2-deficient lymphangioleiomyomatosis-like cells. Am J Respir Cell Mol Biol 2010; 42: 227-234. Odajima N, Betsuyaku T, Nasuhara Y, et al. Matrix metalloproteinases in blood from patients with LAM. Respir Med 2009; 103: 124-129.

4 Li C, Zhang E, Su Y, et al. Rapamycin-insensitive up-regulation of adipocyte phospholipase A2 in tuberous sclerosis and lymphangioleiomyomatosis. PLoS One 2014; 9: e104809.

Yano S. Exacerbation of pulmonary lymphangioleiomyomatosis by exogenous oestrogen used for infertility treatment. Thorax 2002; 57: 1085-1086.

Brunelli A, Catalini G, Fianchini A. Pregnancy exacerbating unsuspected mediastinal lymphangioleiomyomatosis and chylothorax. Int J Gynaecol Obstet 1996; 52: 289-229. 

An immunocytochemical study. Am J Clin Pathol 1990; 93: 609-614.

58 Logginidou H, Ao X, Russo I, et al. Frequent estrogen and progesterone receptor immunoreactivity in renal angiomyolipomas from women with pulmonary lymphangioleiomyomatosis. Chest 2000; 117: 25-30.

59 Taveira-Dasilva AM, Stylianou MP, Hedin CJ, et al. Decline in lung function in patients with lymphangioleiomyomatosis treated with or without progesterone. Chest 2004; 126: 1867-1874.

60 Howe SR, Gottardis MM, Everitt JI, et al. Estrogen stimulation and tamoxifen inhibition of leiomyoma cell growth in vitro and in vivo. Endocrinology 1995; 136: 4996-5003.

$61 \mathrm{Yu}$ J, Astrinidis A, Howard S, et al. Estradiol and tamoxifen stimulate LAM-associated angiomyolipoma cell growth and activate both genomic and nongenomic signaling pathways. Am J Physiol Lung Cell Mol Physiol 2004; 286: L694-L700.

62 Yu JJ, Robb VA, Morrison TA, et al. Estrogen promotes the survival and pulmonary metastasis of tuberin-null cells. Proc Natl Acad Sci USA 2009; 106: 2635-2640.

$63 \mathrm{Gu} \mathrm{X}, \mathrm{Yu}$ JJ, Ilter D, et al. Integration of mTOR and estrogen-ERK2 signaling in lymphangioleiomyomatosis pathogenesis. Proc Natl Acad Sci USA 2013; 110: 14960-14965.

64 Glassberg MK, Elliot SJ, Fritz J, et al. Activation of the estrogen receptor contributes to the progression of pulmonary lymphangioleiomyomatosis via matrix metalloproteinase-induced cell invasiveness. J Clin Endocrinol Metab 2008; 93: 1625-1633.

65 Travis WD, Colby TV, Corrin B, et al. Histological Typing of Lung and Pleural Tumours. Berlin, Springer, 1999.

66 Martignoni G, Pea M, Reghellin D, et al. Molecular pathology of lymphangioleiomyomatosis and other perivascular epithelioid cell tumors. Arch Pathol Lab Med 2010; 134: 33-40.

67 McCormack FX, Travis WD, Colby TV, et al. Lymphangioleiomyomatosis: calling it what it is: a low-grade, destructive, metastasizing neoplasm. Am J Respir Crit Care Med 2012; 186: 1210-1212.

68 Inoki K, Corradetti MN, Guan KL. Dysregulation of the TSC-mTOR pathway in human disease. Nat Genet 2005; 37: 19-24.

69 Goncharova EA, Goncharov DA, Lim PN, et al. Modulation of cell migration and invasiveness by tumor suppressor TSC2 in lymphangioleiomyomatosis. Am J Respir Cell Mol Biol 2006; 34: 473-480.

70 Kumasaka T, Seyama K, Mitani K, et al. Lymphangiogenesis-mediated shedding of LAM cell clusters as a mechanism for dissemination in lymphangioleiomyomatosis. Am J Surg Pathol 2005; 29: 1356-1366.

71 Chilosi M, Pea M, Martignoni G, et al. Cathepsin-k expression in pulmonary lymphangioleiomyomatosis. Mod Pathol 2009; 22: 161-166. 1052-1057. McCormack FX. Lymphangioleiomyomatosis: a clinical update. Chest 2008; 133: 507-516.

74 Johnson SR, Whale CI, Hubbard RB, et al. Survival and disease progression in UK patients with lymphangioleiomyomatosis. Thorax 2004; 59: 800-803.

75 Cohen MM, Pollock-BarZiv S, Johnson SR. Emerging clinical picture of lymphangioleiomyomatosis. Thorax 2005; 60: 875-879.

76 Almoosa KF, Ryu JH, Mendez J, et al. Management of pneumothorax in lymphangioleiomyomatosis: effects on recurrence and lung transplantation complications. Chest 2006; 129: 1274-1281. Ryu JH, Doerr CH, Fisher SD, et al. Chylothorax in lymphangioleiomyomatosis. Chest 2003; 123: 623-627.

78 Matsui K, Tatsuguchi A, Valencia J, et al. Extrapulmonary lymphangioleiomyomatosis (LAM): clinicopathologic features in 22 cases. Hum Pathol 2000; 31: 1242-1248.

79 Avila NA, Kelly JA, Chu SC, et al. Lymphangioleiomyomatosis: abdominopelvic CT and US findings. Radiology 2000; 216: 147-153.

80 Avila NA, Bechtle J, Dwyer AJ, et al. Lymphangioleiomyomatosis: CT of diurnal variation of lymphangioleiomyomas. Radiology 2001; 221: 415-421.

81 Lu HC, Wang J, Tsang YM, et al. Lymphangioleiomyomatosis initially presenting with abdominal pain: a case report. Clin Imaging 2003; 27: 166-170.

82 Wong YY, Yeung TK, Chu WCW. Atypical presentation of lymphangioleiomyomatosis as acute abdomen: CT diagnosis. AJR Am J Roentgenol 2003; 181: 284-285.

83 Yeoh ZW, Navaratnam V, Bhatt R, et al. Natural history of angiomyolipoma in lymphangioleiomyomatosis: implications for screening and surveillance. Orphanet J Rare Dis 2014; 9: 151.

84 Rakowski SK, Winterkorn EB, Paul E, et al. Renal manifestations of tuberous sclerosis complex: incidence, prognosis, and predictive factors. Kidney Int 2006; 70: 1777-1782.

85 Nelson CP, Sanda MG. Contemporary diagnosis and management of renal angiomyolipoma. J Urol 2002; 168 $1315-1325$.

86 Steiner MS, Goldman SM, Fishman EK, et al. The natural history of renal angiomyolipoma. J Urol 1993; 150: $1782-1786$.

87 Yamakado K, Tanaka N, Nakagawa T, et al. Renal angiomyolipoma: relationships between tumor size, aneurysm formation, and rupture. Radiology 2002; 225: 78-82.

88 van Baal JG, Smits NJ, Keeman JN, et al. The evolution of renal angiomyolipomas in patients with tuberous sclerosis. J Urol 1994; 152: 35-38.

89 Krueger DA, Northrup H, International Tuberous Sclerosis Complex Consensus Group. Tuberous sclerosis complex surveillance and management: recommendations of the 2012 international tuberous sclerosis complex consensus conference. Pediatr Neurol 2013; 49: 255-265.

90 Taveira-DaSilva AM, Stylianou MP, Hedin CJ, et al. Maximal oxygen uptake and severity of disease in lymphangioleiomyomatosis. Am J Respir Crit Care Med 2003; 168: 1427-1431.

91 Hayashida M, Seyama K, Inoue Y, et al. The epidemiology of lymphangioleiomyomatosis in Japan: a nationwide cross-sectional study of presenting features and prognostic factors. Respirology 2007; 12: 523-530.

92 Taveira-DaSilva AM, Steagall WK, Rabel A, et al. Reversible airflow obstruction in lymphangioleiomyomatosis Chest 2009; 136: 1596-1603.

93 Avila NA, Chen CC, Chu SC, et al. Pulmonary lymphangioleiomyomatosis: correlation of ventilation-perfusion scintigraphy, chest radiography, and CT with pulmonary function tests. Radiology 2000; 214: 441-446. 
94

95

Matsui K, Beasley MB, Nelson WK, et al. Prognostic significance of pulmonary lymphangioleiomyomatosis histologic score. Am J Surg Pathol 2001; 25: 479-484.

Avila NA, Kelly JA, Dwyer AJ, et al. Lymphangioleiomyomatosis: correlation of qualitative and quantitative thin-section CT with pulmonary function tests and assessment of dependence on pleurodesis. Radiology 2002; 223: 189-197.

Paciocco G, Uslenghi E, Bianchi A, et al. Diffuse cystic lung diseases: correlation between radiologic and functional status. Chest 2004; 125: 135-142.

Johnson SR, Tattersfield A. Decline in lung function in lymphangioleiomyomatosis: relation to menopause and progesterone treatment. Am I Respir Crit Care Med 1999; 160: 628-633.

Baldi BG, Freitas CS, Araujo MS, et al. Clinical course and characterisation of lymphangioleiomyomatosis in a Brazilian reference centre. Sarcoidosis Vasc Diffuse Lung Dis 2014; 31: 129-135.

McCormack FX, Inoue Y, Moss J, et al. Efficacy and safety of sirolimus in lymphangioleiomyomatosis. $N$ Engl J Med 2011; 364: 1595-1606.

Chang WYC, Cane JL, Kumaran M, et al. A 2-year randomised placebo-controlled trial of doxycycline for lymphangioleiomyomatosis. Eur Respir J 2014; 43: 1114-1123.

348-382.

Silverstein EF, Ellis K, Wolff M, et al. Pulmonary lymphangiomyomatosis. Am J Radiol 1974; 120: 832-850.

Oprescu N, McCormack FX, Byrnes S, et al. Clinical predictors of mortality and cause of death in lymphangioleiomyomatosis: a population-based registry. Lung 2013; 191: 35-42.

Kitaichi M, Nishimura K, Itoh H, et al. Pulmonary lymphangioleiomyomatosis: a report of 46 patients including a clinicopathologic study of prognostic factors. Am J Respir Crit Care Med 1995; 151: 527-533.

Celli BR, Cote CG, Marin JM, et al. The body-mass index, airflow obstruction, dyspnea, and exercise capacity index in chronic obstructive pulmonary disease. N Engl J Med 2004; 350: 1005-1012.

Seyama K, Kumasaka T, Souma S, et al. Vascular endothelial growth factor-D is increased in serum of patients with lymphangioleiomyomatosis. Lymphat Res Biol 2006; 4: 143-152.

Young LR, Inoue Y, McCormack FX. Diagnostic potential of serum VEGF-D for lymphangioleiomyomatosis. N Engl J Med 2008; 358: 199-200.

Glasgow CG, Avila NA, Lin JP, et al. Serum vascular endothelial growth factor-D levels in patients with lymphangioleiomyomatosis reflect lymphatic involvement. Chest 2009; 135: 1293-1300.

Young LR, Vandyke R, Gulleman PM, et al. Serum vascular endothelial growth factor-D prospectively distinguishes lymphangioleiomyomatosis from other diseases. Chest 2010; 138: 674-681.

Young LR, Lee HS, Inoue Y, et al. Serum VEGF-D concentration as a biomarker of lymphangioleiomyomatosis severity and treatment response: a prospective analysis of the Multicenter International Lymphangioleiomyomatosis Efficacy of Sirolimus (MILES) trial. Lancet Respir Med 2013; 1: 445-452.

Kumasaka T, Seyama K, Mitani K, et al. Lymphangiogenesis in lymphangioleiomyomatosis: its implication in the progression of lymphangioleiomyomatosis. Am J Surg Pathol 2004; 28: 1007-1016.

Ji RC. Lymphatic endothelial cells, lymphangiogenesis, and extracellular matrix. Lymphat Res Biol 2006; 4: $83-100$.

Matsui K, Takeda K, Yu Z-X, et al. Role for activation of matrix metalloproteinases in the pathogenesis of pulmonary lymphangioleiomyomatosis. Arch Pathol Lab Med 2000; 124: 267-275.

Krymskaya VP, Shipley JM. Lymphangioleiomyomatosis: a complex tale of serum response factor-mediated tissue inhibitor of metalloproteinase-3 regulation. Am J Respir Cell Mol Biol 2003; 28: 546-550.

Zhe X, Yang Y, Jakkaraju S, et al. Tissue inhibitor of metalloproteinase-3 downregulation in lymphangioleiomyomatosis. Am J Respir Cell Mol Biol 2003; 28: 504-511.

Moses MA, Harper J, Folkman J. Doxycycline treatment for lymphangioleiomyomatosis with urinary monitoring for MMPs. N Engl J Med 2006; 324: 2621-2622.

Pimenta SP, Baldi BG, Kairalla RA, et al. Doxycycline use in patients with lymphangioleiomyomatosis: biomarkers and pulmonary function response. J Bras Pneumol 2013; 39: 5-15.

Taylor JR, Ryu J, Colby TV, et al. Lymphangioleiomyomatosis. Clinical course in 32 patients. N Engl J Med 1990; 323: 1254-1260.

Eliasson AH, Phillips YY, Tenholder MF. Treatment of lymphangioleiomyomatosis: a meta-analysis. Chest 1989; 96: 1352-1355.

Rossi GA, Balbi B, Oddera S, et al. Response to treatment with an analog of luteinizing-hormone-releasing hormone in a patient with pulmonary lymphangioleiomyomatosis. Am Rev Respir Dis 1991; 143: 174-176.

Medeiros P, Kairalla RA, Pereira CAC, et al. GnRH analogs X progesterone-lung function evolution in two treatment cohort groups in lymphangioleiomyomatosis (LAM). Am J Respir Crit Care Med 2003; 167 : A953.

de la Fuente J, Páramo C, Román F, et al. Lymphangioleiomyomatosis: unsuccessful treatment with luteinizing-hormone-releasing hormone analogues. Eur J Med 1993; 2: 377-378.

Harari S, Cassandro R, Chiodini I, et al. Effect of a gonadotrophin-releasing hormone analogue on lung function in lymphangioleiomyomatosis. Chest 2008; 133: 448-454.

McCarty KS, Mossler JA, McLelland R, et al. Pulmonary lymphangiomyomatosis responsive to progesterone. N Engl J Med 1980; 303: 1461-1465.

Sieker HO, McCarty KS Jr. Lymphangiomyomatosis: a respiratory illness with an endocrinologic therapy. Trans Am Clin Climatol Assoc 1987; 99: 57-67.

Krymskaya VP, Goncharova EA. PI3K/mTORC1 activation in hamartoma syndromes: therapeutic prospects. Cell Cycle 2009; 8: 403-413.

Bissler JJ, McCormack FX, Young LR, et al. Sirolimus for angiomyolipoma in tuberous sclerosis complex or lymphangioleiomyomotosis. N Engl J Med 2008; 358: 140-151.

Taveira-DaSilva AM, Hathaway O, Stylianou M, et al. Changes in lung function and chylous effusions in patients with lymphangioleiomyomatosis treated with sirolimus. Ann Intern Med 2011; 154: 797-805.

Moua T, Olson EJ, Jean HC, et al. Resolution of chylous pulmonary congestion and respiratory failure in lymphangioleiomyomatosis with sirolimus therapy. Am J Respir Crit Care Med 2012; 186: 389-390.

Yao J, Taveira-DaSilva AM, Jones AM, et al. Sustained effects of sirolimus on lung function and cystic lung lesions in lymphangioleiomyomatosis. Am J Respir Crit Care Med 2014; 190: 1273-1282. 
131 Ando $\mathrm{K}$, Kurihara $\mathrm{M}$, Kataoka $\mathrm{H}$, et al. The efficacy and safety of low-dose sirolimus for treatment of lymphangioleiomyomatosis. Respir Investig 2013; 51: 175-183.

132 Inoue Y, McCormack FX, Lee HS, et al. The MILES Trial: the effect of Asian race on outcomes in patients with lymphangioleiomyomatosis. Am J Respir Crit Care Med 2012; 185: A4444.

133 Krueger DA, Care MM, Holland K, et al. Everolimus for subependymal giant-cell astrocytomas in tuberous sclerosis. N Engl J Med 2010; 363: 1801-1811.

134 Franz DN, Belousova E, Sparagana S, et al. Efficacy and safety of everolimus for subependymal giant cell astrocytomas associated with tuberous sclerosis complex (EXIST-1): a multicentre, randomised, placebo-controlled phase 3 trial. Lancet 2013; 381: 125-132.

135 Bissler JJ, Kingswood JC, Radzikowska E, et al. Everolimus for angiomyolipoma associated with tuberous sclerosis complex or sporadic lymphangioleiomyomatosis (EXIST-2): a multicentre, randomised, double-blind, placebo-controlled trial. Lancet 2013; 381: 817-824.

136 Goldberg HJ, Harari S, Cottin V, et al. Everolimus for the treatment of lymphangioleiomyomatosis: a phase II study. Eur Respir J 2015; 46: 783-794.

137 Finlay GA, Malhowski AJ, Liu Y, et al. Selective inhibition of growth of tuberous sclerosis complex 2 null cells by atorvastatin is associated with impaired Rheb and Rho GTPase function and reduced mTOR/S6 kinase activity. Cancer Res 2007; 67: 9878-9886.

138 Finlay GA, Malhowski AJ, Polizzi K, et al. Renal and liver tumors in Tsc2(+/-) mice, a model of tuberous sclerosis complex, do not respond to treatment with atorvastatin, a 3-hydroxy-3-methylglutarylcoenzyme A reductase inhibitor. Mol Cancer Ther 2009; 8: 1799-1807.

139 Goncharova EA, Goncharov DA, Fehrenbach M, et al. Prevention of alveolar destruction and airspace enlargement in a mouse model of pulmonary lymphangioleiomyomatosis (LAM). Sci Transl Med 2012; 4: 154ra134.

140 Atochina-Vasserman EN, Goncharov DA, Volgina AV, et al. Statins in lymphangioleiomyomatosis. Simvastatin and atorvastatin induce differential effects on tuberous sclerosis complex 2-null cell growth and signaling. Am J Respir Cell Mol Biol 2013; 49: 704-709.

141 El-Chemaly S, Taveira-Da Silva A, Stylianou MP, et al. Statins in lymphangioleiomyomatosis: a word of caution. Eur Respir J 2009; 34: 513-514

142 Taveira-DaSilva AM, Jones AM, Julien-Williams PJ, et al. Retrospective review of combined sirolimus and simvastatin therapy in lymphangioleiomyomatosis. Chest 2015; 147: 180-187.

143 Riemsma R, Forbes CA, Kessels A, et al. Systematic review of aromatase inhibitors in the first-line treatment for hormone sensitive advanced or metastatic breast cancer. Breast Cancer Res Treat 2010; 123: 9-24.

144 Arbiser JL, Govindarajan B, Bai X, et al. Functional tyrosine kinase inhibitor profiling: a generally applicable method points to a novel role of platelet-derived growth factor receptor-beta in tuberous sclerosis. Am J Pathol 2002; 161: 781-786.

145 Govindarajan B, Brat DJ, Csete M, et al. Transgenic expression of dominant negative tuberin through a strong constitutive promoter results in a tissue-specific tuberous sclerosis phenotype in the skin and brain. J Biol Chem 2005; 280: 5870-5874.

146 Zhang $\mathrm{H}$, Bajraszewski N, Wu E, et al. PDGFRs are critical for PI3K/Akt activation and negatively regulated by mTOR. J Clin Invest 2007; 117: 730-738.

147 Govindarajan B, Willoughby L, Band $\mathrm{H}$, et al. Cooperative benefit for the combination of rapamycin and imatinib in tuberous sclerosis complex neoplasia. Vasc Cell 2012; 4: 11. 